that ankylosing spondylitis and aortic dissection without Marfan's syndrome are not coincidentally but causally related, because neither FBN1 nor fibrillin-1 was examined. The extremely rare coexistence of these 2 disorders, however, may support the hypothesis proposed by Simkin. ${ }^{3}$

\section{References}

1. Francke U, Berg MA, Tynan K, Brenn T, Liu W, Aoyama T, et al. A Gly1127Ser mutation in an EGF-like domain of the fibrillin-1 gene is a risk factor for ascending aortic aneurysm and dissection. Am J Hum Genet. 1995;56:1287-96.
2. Milewicz DM, Michael K, Fisher N, Coselli JS, Markello T, Biddinger A. Fibrillin-1 (FBN1) mutations on patients with thoracic aortic aneurysms. Circulation. 1996;94:2708-11.

3. Simkin PA. Acetabular osteitis in ankylosing spondylitis: dose fibrillin figure in its pathogenesis? J Rheumatol. 2001;28:2663-6.

4. Fietta P, Manganelli P. Coexistent Marfan's syndrome and ankylosing spondylitis: a case report. Clin Rheumatol. 2001;20:140-2.

5. Rovensky J, Zlnay M, Zlnay D. Marfans syndrome and ankylosing spondylitis. Isr Med Assoc J. 2003;5:153.

6. Dougados M, van der Linden S, Juhlin R, Huitfeldt B, Amor B, Calin A, et al. The European Spondylarthropathy Study Group preliminary criteria for the classification of spondylarthropathy. Arthritis Rheum. 1991;34:1218-27.

7. Fietta $P$, Manganelli P. Is fibrillin-1 the link between ankylosing spondylitis and Marfan's syndrome? J Rheumatol. 2002;29:1808.

\title{
Total magnetic vascular coupling for arterial revascularization
}

Uwe Klima, MD, PhD, Michael Maringka, MD, Eric Bagaev, MD, S. Kirschner, CM, and Axel Haverich, MD, PhD, Hannover, Germany

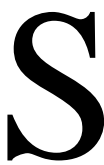
everal new automatic proximal and distal anastomotic devices are in practical use. Their clinical performance, feasibility, and angiographic follow-up have been described. ${ }^{1,2}$ Most authors report on a single automatic anastomosis using a saphenous vein graft. Total arterial revascularization using beating heart techniques is suggested by many authors to be the method of choice for revascularization. ${ }^{3}$ However, to our knowledge, such an operation by means of automatic anastomotic devices has not been reported.

We describe the clinical and angiographic follow-up of a patient who underwent total arterial revascularization on the beating heart in which all anastomoses were performed with an automatic anastomotic magnetic coupling system, the Ventrica Magnetic Vascular Positioner (MVP) Distal Anastomosis System (Ventrica, Inc, Fremont, Calif).

\section{Clinical Summary}

A 69-year-old man with a 12-month history of angina (preoperative New York Heart Association III) underwent cardiac catheterization revealing 3 vessel disease with significant stenosis $(>70 \%)$ of all 3 main coronary arteries. Total arterial revascularization was performed

\footnotetext{
From the Division of Thoracic and Cardiovascular Surgery, Medical School, Hannover, Germany.

Received for publication Aug 11, 2003; revisions requested Sept 2, 2003; accepted for publication Sept 10, 2003.

Address for reprints: Uwe Klima, MD, PhD, Department of Thoracic and Cardiovascular Surgery, Hannover Medical School, 30623 Hannover, Germany (E-mail: klima@thg-mh.hannover.de).

J Thorac Cardiovasc Surg 2004;127:602-3

$0022-5223 / \$ 30.00$

Copyright $\odot 2004$ by The American Association for Thoracic Surgery doi:10.1016/j.jtcvs.2003.09.050
}

using the right and left internal thoracic arteries (ITAs) and the left radial artery (RA). The surgical approach was through a median sternotomy. All target arteries were exposed using the Octopus 4 Tissue Stabilizer and Starfish Heart Positioner (Medtronic, Inc, Minneapolis, Minn). The patient was given an antiplatelet regi-

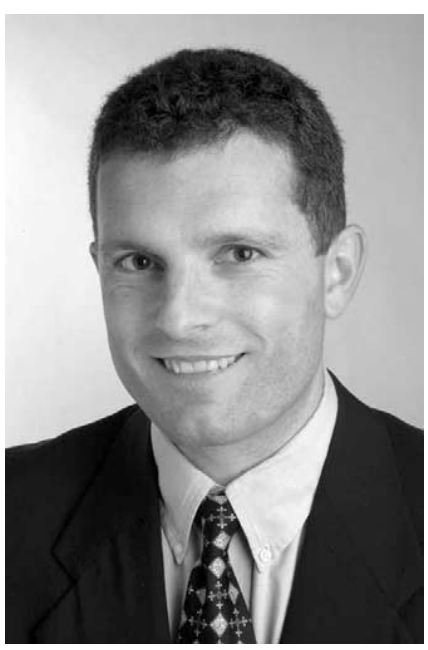

Dr Klima men of $150 \mathrm{mg}$ of clopi-

dogrel (Plavix; Bristol-Myers Squibb, New York, NY) and 100 $\mathrm{mg}$ of aspirin the day before surgery and received $300 \mathrm{IE} / \mathrm{kg}$ of heparin to maintain an activated coagulation time level of more than 350 seconds during the procedure.

All 4 anastomoses were performed with the Ventrica MVP Distal Anastomosis System. The system consists of 6 magnetic clips, with 3 clips forming a set. One magnetic clip set is positioned into the target artery, and the other is positioned into the bypass graft using a preloaded delivery system. These ports then form an anastomosis by magnetic coupling (Figure 1). The first anastomosis created was the left ITA to LAD. The RA was then coupled distally to the circumflex artery, and after shortening the RA, a T-graft anastomosis was also performed to the left ITA with the magnetic coupler. The right coronary artery required an endarterectomy before the fourth automatic anastomosis with the right ITA was performed. The 4 connections were each created in less than 90 seconds.

The patient's intraoperative and postoperative courses were uneventful. A control cardiac catheterization on postoperative day 6 showed all grafts and anastomosis patent (Figure 2). The patient was discharged on postoperative day 10. Ten weeks after surgery the patient is clinically doing well. He is pain free and was able to reach $125 \mathrm{~W}$ for 2 minutes while undergoing an exercise stress test. 


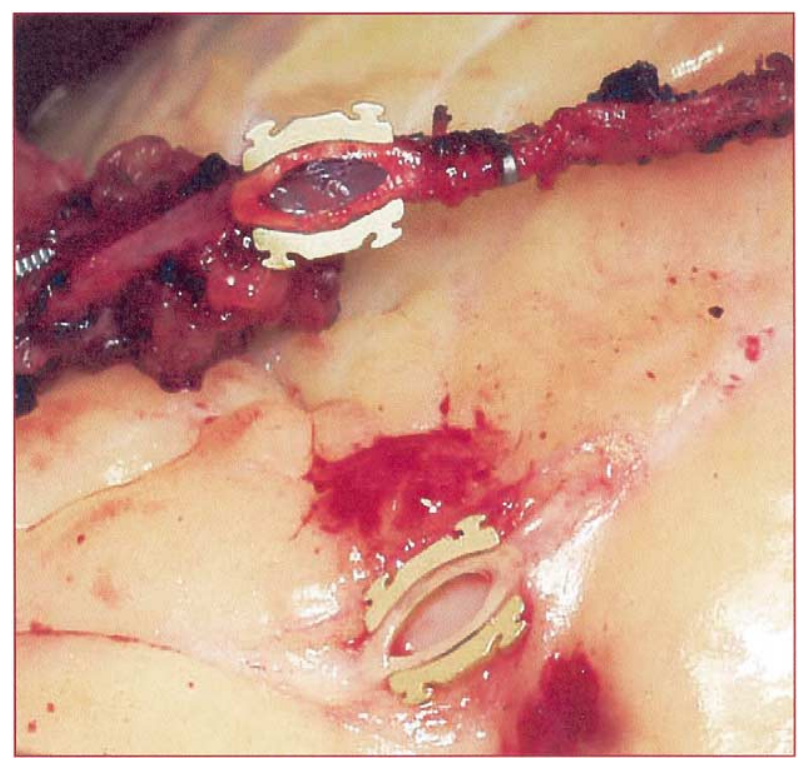

Figure 1. The Ventrica MVP Distal Anastomosis System (Ventrica, Inc, Fremont, Calif) consists of 6 magnetic clips and 2 delivery systems for completion of an anastomosis. Deployed MVP system in graft (above) and target artery (below) before coupling.

\section{Discussion}

The handsewn anastomosis is the "gold standard" for performing coronary artery bypass grafts. However, performing a handsewn anastomosis is more demanding and time-consuming when used in less-invasive approaches such as small access, totally endoscopic, or beating heart surgery. ${ }^{4}$ In conjunction with attempts to reduce the surgical trauma of coronary artery bypass grafting by using lessinvasive approaches, alternative methods for constructing distal anastomoses should be explored and clinically evaluated. It may be hypothesized that by reducing the ischemic time per handsewn anastomosis from 8 to 10 minutes to less than 90 seconds with the automatic anastomosis, the risk of ischemia and its associated complications (eg, arrhythmia) might be decreased significantly.

The concept of magnetic coupling is vastly different from other contemplated micromechanical methods and has several advantages compared with handsewn anastomosis. The device is simple and easy to use, offering the benefit of a quick and repeatable anastomosis. The flexible applicator shaft also helps to facilitate less-invasive procedures. As shown in this case, the device seems to be compatible with ITAs and radial arteries, allowing total arterial revascularization without manipulation of the ascending aorta, as well as with saphenous vein grafts. ${ }^{1}$

One major advantage of the system seems to be the fact that the order of use (proximal, distal, or T-graft anastomoses first) is irrelevant because the design allows either technique. However, currently only end-to-side anastomoses are possible when the target arteries are not in 1 line (eg, obtuse marginal and diagonal branch). Sequential grafts are only possible when the coronary branches are "in line" (eg, diagonal branch and LAD).

One disadvantage of the device is the lack of long-term followup, which is common to all evolving technologies. As of today, predischarge angiographic and clinical follow-up are available ${ }^{1}$ for using magnetic anastomotic technology in coronary surgery. Cur-

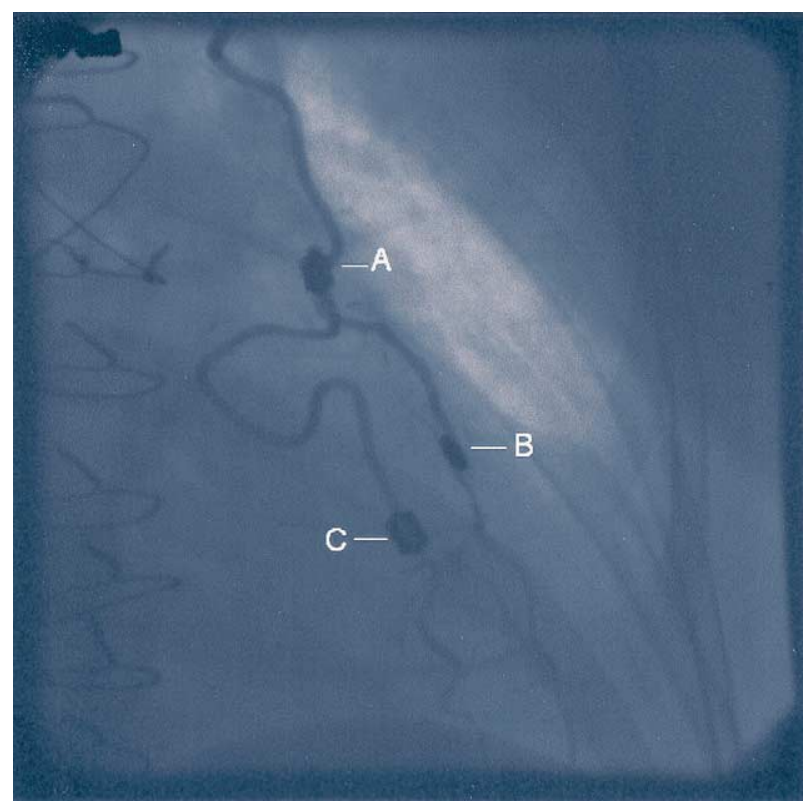

Figure 2. Postoperative left coronary angiogram of MVP anastomoses: $A$, T-graft anastomosis, left ITA to RA. $B$, Left ITA to left anterior descending. $C$, Radial to circumflex artery.

rently 6-month postoperative angiographic and clinical follow-up data are also being collected as part of a clinical trial. Long-term follow-up is certainly necessary to make this new anastomotic technique comparable with the gold standard: the handsewn anastomosis. Whether intimal hyperplasia or local long-term reaction to the intravascular implant may occur also needs to be observed, because these factors may contribute to long-term patency rates.

\section{Conclusion}

Total arterial revascularization on a beating heart using exclusively automatic anastomotic coupling devices for all anastomoses has not been previously described. The Ventrica MVP System proved to be suitable for all target arteries and grafts including a T-graft anastomosis. The ischemic time during the anastomosis could be reduced significantly, thus decreasing the risk of potential intraoperative ischemia and its associated complications. This technology has the potential to facilitate beating heart procedures by creating a high-quality, reproducible, and rapid anastomosis. The long-term patency of these anastomoses needs to be investigated.

\section{References}

1. Klima U, Falk V, Maringka M, Bargenda S, Badack S, Moritz M, et al. Magnetic vascular coupling for distal anastomosis in coronary artery bypass grafting: a multicenter trial. J Thorac Cardiovasc Surg. 2003; 126:1568-74.

2. Scheltes JS, Heikens M, Pistecky PV, van Andel CJ, Borst C. Assessment of patented coronary end-to-side anastomotic devices usingmicromechanical bonding. Ann Thorac Surg. 2000;70:218-21.

3. Ross DE. Opcab with a reusable stabilizer using all arterial grafts and no aortic manipulation via a sternotomy with shortened skin incision. As good as it gets? Heart Surg Forum. 2003;6(Suppl 1):S33.

4. Mack MJ, Acuff TE, Casimir-Ahn H, Lönnn UJ, Jansen EW. Video assisted coronary bypass grafting on the beating heart. Ann Thorac Surg. 1997;63(6 Suppl):100-3. 